\title{
Vasoactive Intestinal Peptide: Electrophysiologic Activity in the Newborn Heart
}

\author{
ARTHUR S. PICKOFF. SHI NAN WANG. ADRIENNE STOLFI, DAVID RAMAGF., \\ NANCY T. ROSS-ASCUITTO, DONAID W. KYDON, AND ROBERT J. ASCUITTO \\ Section of Pediatric Cardiologl: De'partment of Pediatrics. Tulane Lniversity Scheol of Me'dicince, \\ New Orleans, Lomisiana 70$) 1 / 2$
}

\begin{abstract}
We performed intracardiac electrophysiologic studies of the effects of vasoactive intestinal peptide (VIP, $0.125 \mu \mathrm{g} / \mathrm{kg} / \mathrm{min}$ ) on sinus and atrioventricular (AV) nodal function, intracardiac conduction, and myocardial refractoriness in two groups of neonatal dogs (aged 6-16 d). Group I consisted of eight neonates in whom VIP was administered after bilateral vagotomy and $\beta$-blockade with propranolol. Group II consisted of five neonates studied after vagotomy and propranolol, plus total chemical sympathectomy (6-hydroxydopamine). In both groups, VIP resulted in a significant shortening of sinus cycle length. AV nodal conduction time, measured as the $\mathrm{AH}$ interval (the time from the onset of the atrial electogram to the onset of the His bundle electrogram in the His electrode catheter) during atrial pacing, also shortened after VIP. His-Purkinje conduction time and atrial effective refractory periods were unchanged by VIP. In other experiments, the direct chronotropic effect of VIP was evaluated in five isolated neonatal canine hearts using a modified Langendorff technique. In these hearts, the spontaneous cycle length decreased from $403 \pm 88$ to $293 \pm 69 \mathrm{~ms}$, or -28 $\pm 4 \%$ (mean $\pm \mathrm{SD}$ ), after exposure to 0.1-0.5 nmol of VIP $(p<0.001)$. In nine other newborns (aged 4-16 days), the effect of selective $\alpha_{1}$ - and $\alpha_{2}$-adrenergic receptor blockade on the positive chronotropic effect of VIP was evaluated. The effect of VIP on sinus cycle length was not altered by the $\alpha_{1}$-adrenergic receptor blocker prazosin or by the $\alpha_{2}$ adrenergic receptor blocker yohimbine. These data indicate that, in the neonatal dog, VIP shortens sinus cycle length and $A V$ nodal conduction time but has no effect on infranodal conduction or myocardial refractoriness. We find no evidence that VIP's chronotropic effect is modified by $\alpha$ adrenergic receptor blockade. VIP may play a role in the neural modulation of heart rate and $\mathrm{AV}$ nodal conduction in the neonate. (Pediatr Res 35: 244-249, 1994)
\end{abstract}

\section{Abbreviations}

VIP, vasoactive intestinal peptide

$\mathrm{AV}$, atrioventricular

AH interval, the time from the onset of the atrial electrogram to the onset of the His bundle electrogram in the His electrode catheter

$P A$ interval, the time from the onset of the $P$ wave on the surface ECG to the onset of the atrial electrogram in the His electrode catheter

HV interval, the time from the onset of the His deflection in the His electrode catheter to the onset of ventricular

Received June 1, 1993; accepted September 29. 1993.

Correspondence and reprint requests: Arthur S. Pickoff, M.D.. Department of Pediatrics, Section of Cardiology. Tulane University School of Medicine, 1430 Tulane Ave., New Orleans. LA 70112.

Supported by a grant from the National Institute of Child Health and Human Development (A.S.P.; HD 28929-01). activity, either in the surface ECG or in the His or right ventricular electrode catheter

Classic concepts regarding autonomic nervous system modulation of cardiovascular function have recently been revised since the discovery of a host of neuropeptides that are colocalized with norepinephrine in sympathetic nerves and/or acetylcholine in parasympathetic nerves (1). Although the physiologic significance of these neuropeptides is far from understood, it is believed that at least some of these peptides may participate in the neural regulation of cardiovascular function through one of two fundamental mechanisms: The first, termed cotransmission, refers to a direct action of a neuropeptide on a target cell mediated via specific postsynaptic receptors for that peptide. The second, termed neuromodulation, refers to the ability of a neuropeptide to alter the release or action of another autonomic transmitter (1). Both of these mechanisms represent relatively new concepts in autonomic physiology.

VIP is one of these neuropeptides that has been identified throughout the autonomic nervous system. It is a 28 -amino acid peptide that, within the heart, appears to be most highly localized in the regions of the sinus and $\mathrm{AV}$ nodes and atrial myocardium. It is believed that VIP is most likely colocalized with acetylcholine within cardiac postganglionic parasympathetic nerves (1). It has been suggested that VIP may be physiologically active as a neurotransmitter because it has been shown to increase intrinsic cardiac pacemaker rate, enhance AV nodal conduction, and shorten myocardial refractoriness in vivo and in vitro in adult dogs (2-5). Although the effects of VIP in the adult heart have been well described, there has been little or no information regarding the actions of VIP in the developing heart. At least one study reported that the effect of VIP on heart rate may be very different in the early neonatal period compared with later in life (6). This study also suggested that there might be a link between the cardiovascular effects of VIP and $\alpha$-adrenergic receptor activity in the newborn (6). This is of significance because developmentally determined differences in cardiac chronotropic responses and in intracellular signal transduction in response to $\alpha$ adrenergic stimulation have been previously well documented $(7-10)$. Therefore, the purpose of our study was to characterize the effects of VIP on the electrophysiologic properties of the neonatal canine heart. In addition to assessing the effect of VIP on sinus cycle length (in vivo) and in isolated newborn canine hearts), we also evaluated its effect on intracardiac conduction and myocardial refractoriness. Finally, we studied the effects of $\alpha$-blockade on the cardiac responses to VIP to further explore a possible link between VIP and $\alpha$-adrenergic receptor activity previously reported (6). 


\section{MATERIALS AND METHODS}

In vivo experiments. The effects of VIP on the electrophysiology of the newborn heart were studied in vivo in two groups of neonatal mongrel dogs. All experiments were conducted in accordance with federal guidelines for the care and use of laboratory animals. The first group (group I) consisted of eight puppies aged 6-16 d. The second group (group II) consisted of five puppies aged $8-15 \mathrm{~d}$, in whom sympathetic nerve endings were chemically destroyed by the administration of $50 \mathrm{mg} / \mathrm{kg} / \mathrm{d}$ (intraperitoneally) 6-hydroxydopamine (6-OHDA hydrobromide, Sigma Chemical Co., St. Louis, MO) dissolved in $0.9 \% \mathrm{NaCl}$ plus $0.1 \%$ ascorbic acid for $3 \mathrm{~d}$ before the study. This was performed to eliminate sympathetic nerve activity as a possible cause of the electrophysiologic effects of VIP. The efficacy of chemical sympathectomy in these neonates was assessed by observing a lack of change in sinus cycle length in response to a test dose of tyramine as previously described (11).

On the day of the electrophysiology study, all neonates were anesthetized with sodium pentobarbital $(30 \mathrm{mg} / \mathrm{kg}$ intraperitoneally), intubated, and mechanically ventilated (Harvard model 613 , South Natick, MA). Arterial blood gases and blood pressure were monitored through a cannula placed in the left femoral artery. A double lumen cannula was placed in the left femoral vein for the administration of drugs and infusion of VIP. Via the right femoral vein, a 4 French quadipolar electrical catheter (1$\mathrm{mm}$ interelectrode spacing) was positioned in the high right atrium for pacing the atrium and recording local atrial electrogram activity. Through the right jugular vein, a second quadripolar electrical catheter was placed in the apex of the right ventricle for the purpose of pacing the ventricle and recording ventricular electrograms. A third electrical catheter was inserted into the left carotid artery and positioned within the noncoronary cusp of the aorta for recording the low right atrium and $\mathrm{His}$ bundle electrograms. All electrograms were filtered at 30-1000 $\mathrm{Hz}$, amplified, and displayed along with surface ECG lead II and blood pressure using a Gould TA-2000 thermal array chart recorder (Gould Inc., Cleveland, $\mathrm{OH}$ ). Paper speeds of 100-200 $\mathrm{mm} / \mathrm{s}$ were used for measuring intracardiac conduction intervals and myocardial refractory periods. In all neonates, both vagosympathetic trunks were severed and propranolol $\mathrm{HCl} 1 \mathrm{mg} / \mathrm{kg}$ (SoloPak Laboratories, Franklin Park. IL) was administered i.v. In our model, this dose of propranolol completely blocks the increase in heart rate caused by $0.2 \mu \mathrm{g} / \mathrm{kg}$ isoproterenol.

After allowing $20 \mathrm{~min}$ for stabilization, the following electrophysiologic study was performed: First, resting sinus cycle length and intracardiac conduction intervals were recorded. This consisted of recording the intraatrial conduction time (PA interval), AV nodal conduction time (AH interval), and the His-Purkinje conduction time (HV interval). Next, the right atrium was paced with a programmable stimulator (Bloom model DTU-210, Reading, PA) at increasingly rapid rates (cycle lengths of 300 to 160 $\mathrm{ms}$, in 40- to 20 -ms decrements) for $30 \mathrm{~s}$. The $\mathrm{AH}$ interval was measured at each pacing interval to characterize rate-dependent changes in AV nodal conduction time. Finally, atrial and ventricular myocardial refractory periods were determined by performing atrial and ventricular extrastimulation [eight-beat basic drive train (S1) at a cycle length of $260 \mathrm{~ms}$, single extrastimulus (S2) delivered at 10-ms decrements until failure to capture occurred]. The effective refractory period was defined as the longest S1-S2 interval that failed to result in capture of the myocardium. The functional refractory period was defined as the shortest $\mathrm{A} 1$ $\mathrm{A} 2$ interval (during atrial pacing) or the shortest $\mathrm{V} 1-\mathrm{V} 2$ interval (during ventricular pacing) observed in response to any $\mathrm{S} 1-\mathrm{S} 2$ coupling interval.

The entire electrophysiologic study was performed first in the control condition. Next VIP (Peninsula Laboratories, Belmont, CA) was administered through the venous cannula as a continuous infusion at a rate of $0.125 \mu \mathrm{g} / \mathrm{kg} / \mathrm{min}$. This VIP dose is similar to doses administered in previously published in vivo studies of the electrophysiologic effects of VIP $(2,5,6)$. After allowing $15 \mathrm{~min}$ for distribution, sinus cycle length and resting conduction intervals were remeasured and the entire electrophysiologic study was repeated. Thus, the electrophysiologic effects of VIP in in vivo newborn hearts could be determined.

Because of the link between VIP and $\alpha$-adrenergic receptor activity previously reported (6), the following experiments were performed to determine the relationship between $\alpha_{1}$ - and $\alpha_{2}$ adrenergic receptor activity and the effect of VIP in the neonate: In nine vagotomized, propranolol pretreated neonates (aged 4$16 \mathrm{~d})$, a VIP infusion $(0.150-0.250 \mu \mathrm{g} / \mathrm{kg} / \mathrm{min})$ was administered to achieve a decrease in sinus cycle length of approximately $20 \%$ $(19 \pm 3 \%)$. The percent change in blood pressure was also determined. The VIP infusion was then stopped and $30 \mathrm{~min}$ were allowed for the enzymatic degradation of VIP. In four of the neonates, yohimbine (Sigma Chemical Co.. St. Louis, MO), an $\alpha_{2}$-adrenergic receptor blocker, was administered $(1 \mathrm{mg} / \mathrm{kg}$ i.v.) and the VIP infusion was restarted. After the percent changes in sinus cycle length and blood pressure were measured, the VIP infusion was again discontinued. In all nine neonates, the effect of VIP on sinus cycle length and blood pressure was determined before and after administration of the $\alpha_{1}$-adrenergic receptor blocker prazosin $(1 \mathrm{mg} / \mathrm{kg}$ i.v., Sigma Chemical Co. St. Louis. $\mathrm{MO}$ ). $\alpha_{1}$-Adrenergic receptor blockade was verified in these experiments by demonstrating near total attenuation of the elevation in blood pressure in response to a $20-\mu \mathrm{g} / \mathrm{kg}$ test dose of phenylephrine $\mathrm{HCl}$ (Elkins-Sinn Inc., Cherry Hill. NJ). The percent increases in systolic and diastolic blood pressure before prazosin were $49 \%$ and $70 \%$; after prazosin the increases were $3 \%$ and $3 \%$.

In vitro experiments. Because the effects of VIP on sinus cycle length and AV nodal conduction were similar to what would be expected from catecholamine stimulation (see Results), the following in vitro experiments were performed to demonstrate that the effects of VIP were direct and not secondary to sympathetic nerve activation (nerve endings possibly not destroved by 6 hydroxydopamine) or effects of circulating catecholamines derived from other chromaffin tissue: Hearts from five neonatal dogs (aged 4-18 d) were rapidly excised through a midline sternotomy after anesthesia with pentobarbital. The hearts were mounted on a modified Langendorff apparatus (12) and underwent retrograde aortic perfusion at constant coronary flow with a solution containing $621.2 \mathrm{pmol} / \mathrm{L}(100 \mu \mathrm{U} / \mathrm{mL})$ insulin, 118 $\mathrm{mM} \mathrm{NaCl}, 4.7 \mathrm{mM} \mathrm{KCl}, 2.4 \mathrm{mM} \mathrm{MgSO}_{4}, 1.2 \mathrm{mM} \mathrm{KH}_{2} \mathrm{PO}_{4}, 25$ $\mathrm{mM} \mathrm{NaHCO}, 2.4-2.6 \mathrm{mM} \mathrm{CaCl}_{2}, 5.5 \mathrm{mM}$ glucose, and $2 \%$ BSA. Hearts were allowed to beat spontaneously and isovolumically against a fluid-filled balloon catheter in the left ventricle After stabilization for $30 \mathrm{~min}$. cycle length was recorded and then VIP, 0.1 or $0.5 \mathrm{nmol}$, was given as a bolus injection over approximately $1 \mathrm{~s}$ into the aortic root. The cardiac cycle length was then continuously recorded until the change induced by the VIP bolus had fully dissipated.

Statistical analysis. For comparing sinus cycle length and all electrophysiologic measurements (conduction intervals and refractory periods) before and after VIP (or before and after administration of the $\alpha$-antagonists), $\ell$ tests for paired observations were performed. Paired $t$ tests and two-way analyses of variance were performed to analyze the interaction between $\alpha$-adrenergic receptor blockade and the effect of VIP on sinus cycle length and blood pressure. A $p$ value $<0.05$ was required to indicate statistical significance. All values are expressed as the mean \pm SD.

\section{RESULTS}

In Vivo Effects of VIP (Tables 1 and 2). Effects of ITP on sinus crcle length and blood pressure. The administration of VIP to both group I and group II neonates caused a significant decrease in sinus cycle length (increase in heart rate) (Fig. 1). In group 1. the sinus cycle length changed from $342 \pm 28$ to $265 \pm 38 \mathrm{~ms}$. 
Table 1. Effects of VIP on sinus clcle length and blood pressure in neonate*

\begin{tabular}{lccccc}
\hline & \multicolumn{2}{c}{ Group I } & \multicolumn{2}{c}{ Group II } \\
\cline { 2 - 5 } & Control & VIP & Control & VIP \\
\hline SCL & $342 \pm 28$ & $265 \pm 38+$ & $336 \pm 22$ & $291 \pm 21 \ddagger$ \\
BP SYS & $60 \pm 7$ & $57 \pm 7$ & $69 \pm 11$ & $61 \pm 10 \ddagger$ \\
BP DIA & $26 \pm 3$ & $25 \pm 2$ & $33 \pm 5$ & $28 \pm 6 \ddagger$ \\
\hline
\end{tabular}

*All values are means $\pm \mathrm{SD} ; n=8$ for group $\mathrm{I} ; n=5$ for group II. $\mathrm{SCL}$, sinus cycle length (ms): BP SYS, systolic blood pressure $(\mathrm{mm} \mathrm{Hg})$ : BP DIA, diastolic blood pressure $(\mathrm{mm} \mathrm{Hg})$. VIP $=0.125 \mu \mathrm{g} / \mathrm{kg} / \mathrm{min}$.

$+p<0.001$ compared with control (paired $t$ tests).

$\ddagger p<0.01$ compared with control (paired $t$ tests).

Table 2. Electrophysiologic effects of VIP in vivo in neonate*

\begin{tabular}{lcccc} 
& \multicolumn{2}{c}{ Group I } & \multicolumn{2}{c}{ Group II } \\
\cline { 2 - 5 } & Control & VIP & Control & VIP \\
\hline PA & $13 \pm 4$ & $7 \pm 3 \dagger$ & $10 \pm 7$ & $7 \pm 6$ \\
$\mathrm{AH}$ & $50 \pm 7$ & $44 \pm 6 \dagger$ & $47 \pm 5$ & $41 \pm 5 \ddagger$ \\
$\mathrm{HV}$ & $19 \pm 4$ & $19 \pm 4$ & $17 \pm 2$ & $16 \pm 2$ \\
$\mathrm{AH}_{20}$ & $74 \pm 12$ & $53 \pm 10 \$$ & $75 \pm 8$ & $56 \pm 8 \S$ \\
$\mathrm{AERP}$ & $59 \pm 8$ & $59 \pm 14$ & $50 \pm 14$ & $61 \pm 21$ \\
$\mathrm{AFRP}$ & $91 \pm 17$ & $93 \pm 19$ & $82 \pm 8$ & $90 \pm 9 \ddagger$ \\
VERP & $130 \pm 12$ & $123 \pm 8 \dagger$ & $137 \pm 12$ & $133 \pm 14$ \\
VFRP & $156 \pm 10$ & $148 \pm 9 \ddagger$ & $158 \pm 6$ & $155 \pm 6$
\end{tabular}

* All values are means \pm SD in ms; group I, $n=8$ : Group II, $n=5$. PA, intraatrial conduction time: AH, AV nodal conduction time: HV, His-Purkinje conduction time; $\mathrm{AH}_{2(x)}, \mathrm{AV}$ nodal conduction time at paced atrial cycle length of $200 \mathrm{~ms}$; AERP, atrial effective refractory period; AFRP, atrial functional refractory period: VERP, ventricular effective refractory period: VFRP, ventricular functional refractory period. VIP $=0.125 \mu \mathrm{g} / \mathrm{kg} / \mathrm{min}$.

$+p<0.01$ compared with control (paired $t$ tests).

$\ddagger p<0.05$ compared with control (paired $\iota$ tests).

$\S p<0.001$ compared with control (paired $t$ tests).

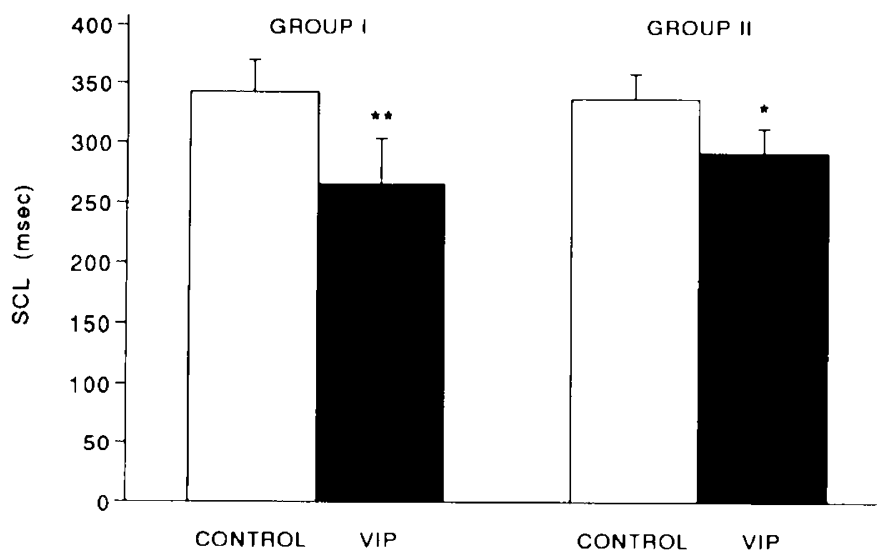

Fig. 1. The effect of VIP infusion on sinus cycle length in vivo. Sinus cycle length (SCL) is plotted in the control condition and after VIP infusion in group I $(n=8)$ and group II $(n=5)$ neonates. VIP caused a significant decrease in SCL both in group I and in chemically sympathectomized neonates (group II). ${ }^{*}, p<0.01:^{* *}, p<0.001$ compared with control (paired $t$ test).

representing a $23 \pm 7 \%$ decrease $(p<0.001)$. In the sympathectomized neonates (group II), the change in sinus cycle length was slightly less $[336 \pm 22$ to $291 \pm 21 \mathrm{~ms}$, or a $14 \pm 3 \%$ decrease $(p<0.01)]$. Thus, even after chemical destruction of sympathetic nerve endings, VIP decreased sinus cycle length in these newborn puppies. In group I neonates, neither systolic or diastolic blood pressure changed in response to VIP, whereas in group II, systolic blood pressure fell by $12 \pm 6 \%(p<0.01)$ and diastolic blood pressure by $16 \pm 6 \%(p<0.01)$.
Effects of IIP on intracardiac conduction. Intraatrial conduction time, measured as the PA interval, decreased by $42 \pm 22 \%$ $(p<0.01)$ in group I neonates, and a similar but not significant change was observed in group II $(30 \pm 19 \%, p=0.17)$. HisPurkinje conduction time (HV interval) was unaffected by the infusion of VIP.

In both groups. AV nodal conduction time ( $\mathrm{AH}$ interval) decreased significantly in response to VIP. In group I, the mean resting $\mathrm{AH}$ interval decreased from $50 \pm 7 \mathrm{~ms}$ to $44 \pm 6 \mathrm{~ms}$, or by $11 \pm 8 \%(p<0.01)$. Similar changes $(12 \pm 7 \%)$ were observed in the sympathectomized neonates $(p<0.05)$. Changes in $\mathrm{AV}$ nodal conduction were more pronounced as the rate-dependent slowing of AV nodal conduction was probed by rapid atrial pacing (Figs. 2 and 3). As seen in Figure 3, the curve describing the relationship between the change in the $\mathrm{AH}$ interval and atrial paced rate was shifted upward after VIP infusion. At each paced cycle length, AV nodal conduction was faster in the presence of VIP. For example, at a paced cycle length of $200 \mathrm{~ms}$, the mean $\mathrm{AH}$ interval decreased from $74 \pm 12$ to $53 \pm 10 \mathrm{~ms}$ after VIP in group I $(p<0.001)$. This represents a $28 \pm 8 \%$ decrease in AV nodal conduction time in response to VIP. Again, as with sinus cycle length, the sympathectomized neonates (group II) demon-
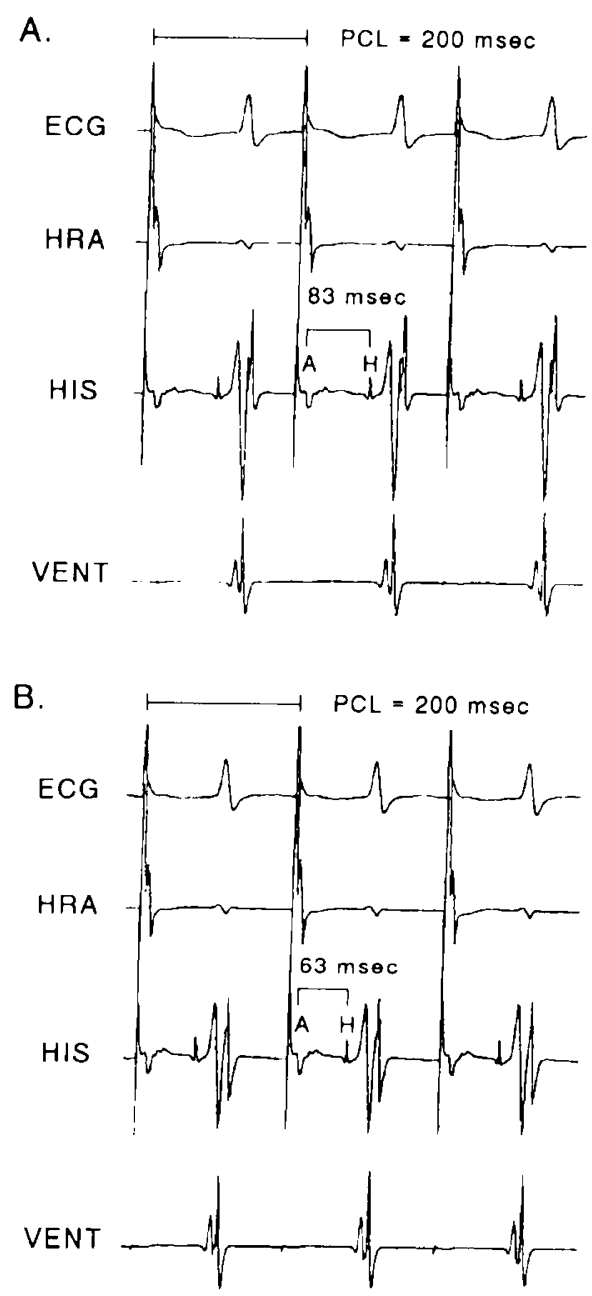

Fig. 2. Changes in $A V$ nodal conduction time after VIP. In each panel, the following are displayed: surface ECG lead II, electrograms recorded by the high right atrial electrode catheter $(H R .4)$, the His bundle electrode catheter $(H I S)$, and the right ventricle catheter (IENT). AV nodal conduction time ( $\mathrm{AH}$ interval) is measured as the interval from the onset of the atrial electrogram in the HIS catheter $(A)$ to the onset of the hundle of His deflection $(H)$. In these examples, the heart is paced at a cycle length of $200 \mathrm{~ms}(P C L=200 \mathrm{~ms})$. Before VIP ( panel $A)$, the $\mathrm{AH}$ interval measures $83 \mathrm{~ms}$. After VIP (panel $B$ ), the AH interval shortens to $63 \mathrm{~ms}$. 

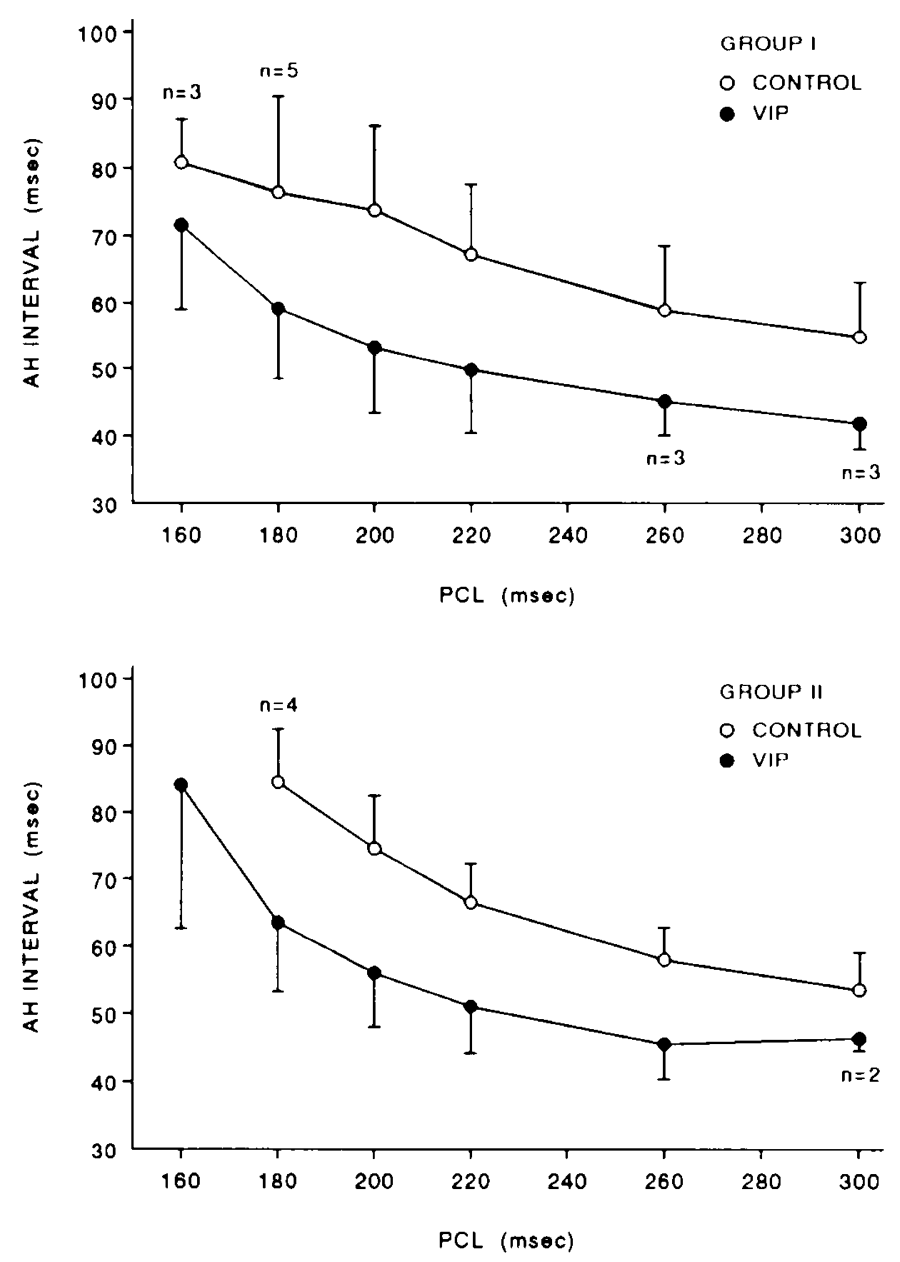

Fig. 3. AV nodal conduction curves in neonatal dogs before (control) and during the infusion of VIP. AV nodal conduction time (AH interval) is plotted as a function of paced atrial cycle length $(P C L)$ in both group I (upper panel) and group II (lower panel) neonates. In both groups, and at each paced cycle length, the $\mathrm{AH}$ interval was shortened during the infusion of VIP.

strated a similar change in AV nodal conduction with atrial pacing during the VIP infusion $(25 \pm 4 \%$ decrease in $\mathrm{AH}$ interval at paced cycle length $200 \mathrm{~ms}, p<0.001$ ). Thus, in addition to decreasing sinus cycle length, VIP also shortened AV nodal conduction time in the neonatal heart.

Effects of VIP on atrial and ventricular refractory periods. Atrial effective refractory periods were unchanged by VIP in both groups. Atrial functional refractory periods were unchanged by VIP in the group I neonates and prolonged slightly $(10 \pm 5 \%$. $p<0.05$ ) after VIP in group II. With respect to ventricular refractory periods, in group I both the effective and functional refractory periods decreased $(6 \pm 4 \%$ and $5 \pm 5 \%$, respectively) during the VIP infusion. These small (but statistically significant) changes were not detected in the sympathectomized neonates (group II), in whom VIP resulted in no change in either the effective or functional refractory period of the ventricle.

Effect of $\alpha$-adrenergic receptor blockers on cardiac chronotropic response to VIP (Table 3). The change in sinus cycle length caused by VIP was unaltered by $\alpha_{1}$-adrenergic receptor blockade with prazosin. Before prazosin, VIP infusion resulted in a $19 \pm$ $3 \%$ decrease in sinus cycle length. Prazosin alone increased the resting sinus cycle length by $4 \pm 1 \%$. After prazosin, the decrease in sinus cycle length in response to VIP was $18 \pm 2 \%$. The interaction of the effect of prazosin administration on the VIP chronotropic response was not statistically significant $(p=0.48)$. Similarly, no interaction was detected in the response of systolic and diastolic blood pressure to VIP in the presence of prazosin.
Concerning $\alpha_{2}$-adrenergic receptor blockade, the chronotropic response to VIP was similar before and after administration of the selective $\alpha_{2}$-adrenergic receptor blocker, yohimbine. Before yohimbine, VIP caused a $17 \pm 3 \%$ decrease in sinus cycle length. Yohimbine alone slowed resting sinus cycle length by $4 \pm 2 \%$. After yohimbine, VIP decreased sinus cycle length by $16 \pm 2 \%$. Again, no interaction was demonstrated between the chronotropic response to VIP and yohimbine administration $(p=0.57)$. Changes in blood pressure in response to VIP also were unaffected by pretreatment with yohimbine. Thus, in these experiments neither $\alpha_{1}$ - or $\alpha_{2}$-adrenergic receptor blockade modified the response of heart rate (sinus cycle length) or blood pressure to VIP.

Effect of IIP on Automaticity in Isolated Hearts. To further exclude circulating catecholamines or residual intact sympathetic nerve terminals (in group II) as mediators of the increased automaticity observed in vivo in response to VIP infusion, we studied the effects of VIP on pacemaker automaticity in isolated. perfused neonatal canine hearts $(n=5)$. In these experiments, VIP $(0.1$ or $0.5 \mathrm{nmol})$ decreased the spontaneous pacemaker cycle length from a mean value of $403 \pm 89 \mathrm{~ms}$ to $293 \pm 69 \mathrm{~ms}$ $(p<0.001)$. The percent decrease in sinus cycle length observed in response to VIP in vitro was similar to that observed in the intact neonates [28 $\pm 4 \%$ in vitro): $19 \pm 7 \%$ in vivo (groups I and II combined)].

\section{DISCUSSION}

Vasoactive intestinal peptide has been identified histochemically within the mammalian heart. It is found within cardiac nerves in high concentrations in the sinus and AV nodes and to a lesser extent within the atrial and ventricular myocardium. VIP-containing cell bodies are also demonstrable and are localized in a distribution that is similar to the distribution of vagal postganglionic cells $(1,2,13-15)$. That VIP may be active in vivo in the neuromodulation of cardiac electrophysiology was suggested by Rigel (16), who demonstrated that VIP administration into the sinus node artery of anesthetized dogs resulted in a significant positive chronotropic effect. This finding complimented earlier in vitro studies in which a positive cardiac chronotropic effect of VIP was observed in a variety of experimental models $(17,18)$. Since then, VIP has been shown to not only increase cardiac pacemaker automaticity but to also shorten $\mathrm{AV}$ nodal conduction time as well as atrial and ventricular refractory periods (2-5). The cellular mechanism of VIP's effect on the heart appears to be mediated via a VIP receptor-triggered increase in adenylate cyclase activity (18). VIP is believed to be released during vagal nerve stimulation and has been implicated as the agent responsible for a significant portion of the acceleration of heart rate noted during vagal stimulation in the presence of atropine $(19,20)$. Therefore, a growing body of evidence, both morphologic and physiologic, indicates that VIP is important in modulating cardiac electrophysiologic characteristics by the autonomic nervous system.

In the present study, we have demonstrated that exogenously administered VIP is also biologically active in the canine neonate. In the neonate, VIP significantly decreased resting sinus cycle length, as well as AV nodal conduction time. Our findings regarding the effect of VIP on sinus cycle length and on AV nodal conduction are similar to those reported by Rigel and Lathrop (2), who studied the cardiac effects of VIP in conscious and anesthetized adult dogs. A very slight shortening of ventricular refractory periods, as reported in the adult (2), was also noted in response to VIP, but only in the sympathetically intact (group I) neonates. Unlike the study in adult dogs, however, we did not observe a shortening of atrial refractoriness after VIP (the atrial functional refractory period actually increased slightly in the sympathectomized neonates). It is not clear why we did not observe the decrease in atrial refractoriness that would have been predicted from the data in the adult $\operatorname{dog}(2)$. We did find, 
PICKOFF ET AI.

Table 3. Effects of $\alpha$-blockade on cardiac responses to VIP*

\begin{tabular}{|c|c|c|c|c|c|c|c|c|}
\hline & \multicolumn{2}{|c|}{ VIP } & \multicolumn{2}{|c|}{$\mathrm{VIP}+$ prazosin } & \multicolumn{2}{|c|}{ VIP } & \multicolumn{2}{|c|}{ VIP + yohimbine } \\
\hline & Pre & Post & Pre & Post & Pre & Post & Pre & Post \\
\hline SCL & $331 \pm 6$ & $268 \pm 9$ & $347 \pm 11$ & $285 \pm 9$ & $329 \pm 2$ & $274 \pm 8$ & $333 \pm 5$ & $281 \pm 8$ \\
\hline BP SYS & $58 \pm 7$ & $52 \pm 9$ & $56 \pm 8$ & $49 \pm 8$ & $59 \pm 8$ & $55 \pm 8$ & $53 \pm 7$ & $50 \pm 13$ \\
\hline BP DIA & $24 \pm 4$ & $22 \pm 5$ & $22 \pm 6$ & $19 \pm 6$ & $25 \pm 3$ & $24 \pm 3$ & $22 \pm 3$ & $21 \pm 5$ \\
\hline
\end{tabular}

* All values are means $\pm \mathrm{SD} ; n=9$ for $\alpha_{1}$-adrenergic receptor blockade (prazosin $1 \mathrm{mg} / \mathrm{kg}$ ): $n=4$ for $\alpha_{2}$-adrenergic receptor blockade (yohimbine $1 \mathrm{mg} / \mathrm{kg}$ ). SCL, sinus cycle length (ms); BP SYS, systolic blood pressure $(\mathrm{mm} \mathrm{Hg})$; BP DIA, diastolic blood pressure $(\mathrm{mm} \mathrm{Hg}) . \mathrm{VIP}=0.150-0.250$ $\mu \mathrm{g} / \mathrm{kg} / \mathrm{min}$. There were no significant differences for VIP alone $\mathrm{ws.}$ VIP plus $\alpha_{1}$ - or $\alpha_{2}$-adrenergic receptor blockade (two-way analysis of variance. interaction effect).

however, that the intraatrial conduction time (the PA interval) shortened significantly after VIP $(37 \pm 21 \%$, groups I and II combined). It is possible, therefore, that the lack of change in atrial refractoriness after VIP may, in fact, reflect some developmental difference in the ionic mechanism(s) controlling repolarization in the immature atrium rather than a lack of VIP receptors in the neonatal atrium. This could explain why intraatrial conduction was shortened by VIP, but atrial refractoriness was not. Assuming that VIP is present and colocalized with acetylcholine within parasympathetic nerves in the neonatal heart, one would expect atrial VIP receptors to be present in addition to cholinergic receptors. There is ample evidence of intact parasympathetic innervation to the newborn canine atrium (21). Detailed immunohistochemical studies of the distribution of VIP and VIP receptors within the developing heart would be needed to help clarify these issues.

Our findings of the effects of VIP in the neonatal canine heart differ from those reported by Mas et al. (6). In that study, VIP was reported to cause no increase in heart rate in young dogs (aged 5-18 d). In fact, heart rate actually decreased after VIP was administered. In a slightly older age group (aged 20-32 d), VIP did increase heart rate, but by only $7 \%$. AV conduction and myocardial refractoriness were not evaluated in this study. In contrast, we did observe a significant decrease in sinus cycle length (increase in heart rate) in young neonates with a VIP infusion. We believe that this decrease in sinus cycle length was, in fact, a direct effect of VIP rather than attributable to a secondary effect of sympathetically derived or circulating catecholamines or other neurohumoral substance(s). The decrease in sinus cycle length noted in our study was not only observed in vagotomized, propranolol-treated neonates (group I), but was also observed in chemically sympathectomized neonates (group II). We did observe, however, that the percent change in sinus cycle length was somewhat greater in the sympathetically intact neonates compared with the sympathectomized neonates (23 versus $14 \%$ ). It is possible that in group I (sympathetic nerves intact) VIP, in addition to a direct effect on sinus cycle length, may also have resulted in some degree of activation of efferent sympathetic neurons, as has been reported in the adult dog (22). Finally, as further evidence of a direct cardiac effect of VIP. a positive chronotropic effect of VIP was also demonstrated in vitro in isolated hearts of similar age. Thus, we believe that VIP does, in fact, increase pacemaker automaticity in the neonatal canine heart, as reported in the adult. We do not know the reasons that our findings differ from the observations of Mas et al. (6).

In our study, we also investigated whether $\alpha$-adrenergic receptor blockade altered the cardiac chronotropic response to VIP. A coupling between $\alpha$-adrenergic receptor activity and the effects of VIP has been suggested in other organ system models. For example, it has previously been demonstrated that $\alpha_{1}$-receptor stimulation can significantly potentiate the increase in intracellular cAMP production caused by VIP. The increase in cAMP observed in response to simultaneous receptor activation is greater than the increase observed with either receptor type alone $(23,24)$. In contrast, $\alpha_{2}$-receptor stimulation has been shown to antagonize the metabolic effects of VIP in isolated rat enterocytes
(25) and to inhibit stimulation of cAMP by VIP in rabbit ciliary processes (26).

In the cardiovascular system. Mas $e t$ al. (6) reported that nonselective $\alpha$-adrenergic receptor blockade with phentolamine significantly potentiated the hypotensive effect of VIP in neonatal dogs. These authors suggested that there might be a complex relationship between $\alpha$-adrenergic receptor activity and the cardiovascular effects of VIP in the neonate. In our study, we observed no significant difference in the positive chronotropic effect of VIP after either $\alpha_{1}$ - or $\alpha_{2}$-adrenergic receptor blockade. In regard to blood pressure, although the decrease in systolic and diastolic blood pressure after VIP plus prazosin was slightly greater than after VIP alone (Table 3), no statistical interaction could be shown between VIP's effect on blood pressure and prazosin administration. Changes in blood pressure in response to VIP were identical before and after yohimbine administration. Therefore, in our experiments, no clear relationship was found between $\alpha$-adrenergic receptor activity and the cardiovascular effects of VIP in the neonatal dog. A possible link between VIP and $\alpha$-adrenergic activity in the neonatal dog might be further investigated using selective adrenergic agonists in addition to selective adrenergic receptor blockers.

In summary, our data demonstrate that VIP is a biologically active neuropeptide in the neonatal heart. VIP significantly decreases sinus cycle length and AV nodal conduction in these hearts. In this study, no clear interaction could be demonstrated between $\alpha$-adrenergic receptor blockade and the effect of VIP on sinus cycle length and blood pressure. A relationship between these two diverse receptor subtypes, however, is not fully excluded and warrants further investigation. Given the electrophysiologic effects of VIP in the neonatal heart, it is likely that VIP plays a role in the regulation of heart rate and blood pressure by the autonomic nervous system.

Acknowledgment. The authors thank Philip J. Kadowitz, Ph.D., for his helpful insight and assistance.

\section{REFERENCES}

1. Corr L 1992 Neuropeptides and the conduction system of the heart. Int $J$ Cardiol 35:1-12

2. Rigef DF. Lathrop DA 1990 Vasoactive intestinal polypeptide facilitates atrioventricular nodal conduction and shortens atrial and ventricular refractory periods in conscious and anesthetized dogs. Circ Res 67:1323-1333

3. Karasawa Y. Furukawa Y, Ren L-M. Takei M. Murakami M, Narita M, Chiba S 1990 Cardiac responses to VIP and VIP-ergic-cholinergic interaction in isolated dog heart preparations. Eur J Pharmacol 187:9-17

4. Kralios AC, Anderson FL. Kralios FA 1990 Myocardial electrophysiological effects of vasoactive intestinal peptide in dogs. Am J Physiol 259:H1559H 1565

5. Rigel DF. Lathrop DA 1991 Vasoactive intestinal polypeptide enhances automaticity of supraventricular pacemakers in anesthetized dogs. Am J Physiol 261:H463-H468

6. Mas MS, Adams DJ, Gelband H 1990 Synergistic hypotensive effect of vasoactive intestinal polypeptide and $\alpha$-blockade with phentolamine. Evidence for vasoactive intestinal peptide $\alpha$-adrenoceptor coupling in the cardiovascular system of newborn dogs. Circ Res 67:986-992

7. Reder RF, Danilo Jr P. Rosen MR 1984 Developmental changes in alpha adrenergic effects on canine Purkinje fiber automaticity. Dev Pharmacol Ther 7:94-108

8. McCormack J, Gelband H, Villafane J, Xu H, Stolfi A, Pickoff AS 1988 In 
vivo demonstration of maturational changes of the chronotropic response to $\alpha$-adrenergic stimulation. Pediatr Res 24:50-54

9. Steinberg SF, Drugge ED, Bilezikian JP. Robinson RB 1985 Acquisition by innervated cardiac myocytes of a pertussis toxin-specific regulatory protein linked to the $\alpha_{1}$-receptor. Science 230:186-188

10. Fleming JW, Wisler PL, Watanabe AM 1992 Signal transctuction by G proteins in cardiac tissues. Circulation 85:420-433

11. Yamasaki S, Stolfi A, Mas MS. Fox LS, Pickoff AS 1991 Rapid attenuation ("fade") of the chronotropic response during vagal stimulation in the canine newborn. Evidence for a prominent neuropeptide $Y$ effect. Circ Res 69 : 406-413

12. Ascuitto RJ, Ross-Ascuitto NT, Ramage D, McDonough KH, Kadowitz PJ 1992 Acetylcholine-induced coronary vasoconstriction and negative inotropy in the neonatal pig heart. Pediatr Res 32:236-242

13. Weihe E, Reinecke M 1981 Peptidergic innervation of the mammalian sinus nodes: vasoactive intestinal polypeptide, neurotensin, substance $P$. Neurosci Lett 26:283-288

14. Weihe E, Reinecke M. Forssmann WG 1984 Distribution of vasoactive intestinal polypeptide-like immunoreactivity in the mammalian heart. Interrelation with neurotensin- and substance P-like immunoreactive nerves. Cell Tissue Res 236:527-540

15. Reinecke M, Forssmann WG 1984 Regulatory peptides (SP, NT, VIP, PHI, ENK) of autonomic nerves in the guinea pig heart. Clin Exp Hypertens [A] 6:1867-187!

16. Rigel DF 1988 Effects of neuropeptides on heart rate in dogs: comparison of VIP, PHI, NPY, CGRP, and NT. Am J Physiol 255:H311-H317
17. Hoover DB 1989 Effects of guinea pig vasoactive intestinal peptide on the isolated perfused guinea pig heart. Peptides 10:343-347

18. Christophe J. Waelbroeck M. Chatelain P. Robberecht P 1984 Hean receptors for VIP. PHI and secretin are able to activate adenylate cyclase and to mediate inotropic and chronotropic effects. Species variations and physiopathology. Peptides 5:341-353,1984

19. Alter III WA, Weiss GK. Priola DV 1973 Vagally induced tachycardia in atropinized dogs: effect of $\beta$-adrenergic blockade. Eur J Pharmacol 24 329-333

20. Hill MRS, Wallick DW, Martin PJ. Levy MN 1990) Attenuation of nonadrenergic, nonmuscarinic, vagally induced tachycardia. ('irculation 82(Suppl III):III-454

21. Pickoff AS. Stolfi A 1990 Modulation of the electrophysiological properties of neonatal canine heart by tonic parasympathetic stimulation. Am J Physio 258:H38-H44

22. Armour JA 1989 Peptidergic modulation of efferent sympathetic neurons in intrathoracic ganglia regulating the canine heart. Proc Soc Exp Biol 191 $60-68$

23. Magistretti PJ, Schorderet M 1984 VIP and noradrenaline act synergistically to increase cyclic AMP in cerebral cortex. Nature 308:280-282

24. Chik CL. Ho AK. Klein DC 1988 Dual receptor regulation of cyclic nucleotides: $\alpha_{i}$-adrenergic potentiation of vasoactive intestinal peptide stimulation of pinealocyte adenosine $3^{\prime}, 5^{\prime}$-monophosphate. Endocrinology 122 $1646-1651$

25. Vidal H, Riou JP 1989 a $\alpha_{2}$-adrenergic stimulation counteracts the metabolic effects of vasoactive intestinal peptide in isolated rat enterocytes. Endocrinology 124:3117-3121

26. Bausher LP. Gregory DS. Sears ML 1989 Alphay-adrenergic and VIP receptors in rabbit ciliary processes interact. ('urr lye Res 8:47-54 